\title{
TUBERCULIN SURVEY IN GOVERNMENT HIGH SCHOOL OF DHARAN MUNICIPALITY
}

\author{
Kumar N*, Baral D D*, Tamrakar S* \\ * B. P. Koirala Institute of Health Sciences, Dharan, Nepal.
}

\section{ABSTRACT}

This survey was done in 682 out of 1672 children tested with Batch of Tuberculin used for Testing (PPD RT 23 with Tween 80) in Jan. 1997 with financial research grant of B.P. Koirala Institute of Health Sciences, Dharan.

Dharan City is situated in Eastern Development Region (EDR) of Nepal where a high percentage of migrated population is residing with very high number of sputum positive cases. The majority of population are from high hills \& mountain region where the Annual Risk of Infection (ARI) is less. This survey was done to know the epidemiological situation of Tuberculosis (TB) in Dharan.

Tuberculin survey was done in Eastern Development Region (EDR) (1994) by National Tuberculosis Centre (NTC) / Japan International Cooperation Agency (JICA) in Saptari \& Morang. The reported result of average Annual Risk of Infection (ARI) is $2.49 \%$ \& $2.38 \%$ respectively.

The mean age of surveyed population was $14.8 \mathrm{yrs}$. The Bacilli Calmette Guerin (BCG) coverage (scar rate) was $38.3 \%$ \& BCG 4 - 8 age group $83.3 \%$ was highest \& it gradually decreased to $37.5 \%$ in $12+$ age group. The average 23 Tween - 8 - Batch of Tuberculin used for Testing (PPD) positive is $33.6 \%$ with $10 \mathrm{~mm}$ induration as cutoff line. Annual Risk of Infection (ARI) based on above was $2.7 \%$ in 9 - 11 age group \& $1.31 \%$ in $12+$ age group. This survey is suggestive of tuberculosis being highly prevalent in Dharan. The survey also showed average ARI to be $2.44 \%$ in Dharan in 10 - 15 yrs age group. The finding is suggestive of high ARI although the populations has migrated from hill \& mountain. Previous report of average ARI in this area was $2.5 \%$ (Morang \& Saptari). The survey result suggests that high priority, effective tuberculosis program is necessary and intensive control program can only give impact to control of tuberculosis in Dharan.

Key Words: Tuberculin survey, school children, BCG coverage, ARI, Effective tuberculosis programme.

\section{INTRODUCTION}

B. P. Koirala Institute of Health Sciences (BPKIHS) is situated in eastern region of Nepal in the city Dharan of Sunsari District. The population of Dharan municipality is 66,457 (1991 census). Most of the population has migrated from mountain \& hills. They belong to low \& middle income group.

Address for correspondence :

Dr. Narayan Kumar

BP Koirala Institute of Health Sciences, Dharan, Nepal.

Email: kumarnarain@yahoo.com

Received Date : $27^{\text {th }}$ Dec., 2004

Accepted Date : $20^{\text {th }}$ June, 2005
A community based tuberculosis clinic is being run by the institute. This clinic is giving regular diagnostic service for all patients coming from all 16 district of Eastern Development Region (EDR) \& neighboring Indian border, while case holding program is only for the Dharan municipality area as per National Tuberculosis Centre (NTC) instructions. 
B.P. Koirala Institute of Health Sciences (BPKIHS) caters to population of lower hills as well as terai. The Tuberculosis (TB) clinic regularly detects 260 - 270 sputum positive cases from Dharan municipality annually (1994 - 1997).

As Mass Miniature Radiography (MMR) for prevalence survey was not possible \& sputum examination is more difficult due to social factor; therefore tuberculin survey was the best alternative applied. ${ }^{1}$ The survey was conducted in school going children under 15 yrs. of age in January 1997 with financial research grant of BPKIHS. Previous reported Annual Risk of Infection (ARI) by National Tuberculosis Centre (NTC) is 4\% for cities, $1.5 \%$ for hilly \& less than $1 \%$ for mountain population. ${ }^{2}$ Tuberculin survey was done in Eastern Development Region (EDR) (1994) by National Tuberculosis Centre (NTC) / Japan International Cooperation Agency (JICA) in Saptari \& Morang. The reported result of average Annual Risk of Infection (ARI) is $2.49 \%$ \& $2.38 \%$ respectively. Training was given to lab technician \& staff nurse for tuberculin test (Injector \& reader) by experts available in the institute.

Earlier, more number of schools were planned for survey. However, our survey team encountered difficulty in their work due to reluctance showed by the school principals (poor response) $\&$ also due to general ignorance. So, the survey was limited to one big public school of Dharan municipality to assess the following:

a. Extent of tuberculosis; estimate incidence and prevalence as compared to the reported incidence.

b. BCG coverage.

c. Have base line data for the trend of tuberculosis by repeating the survey at different intervals (5 -10 years).

\section{MATERIAL \& METHOD}

This survey was done in Jan. 1997. The survey was carried out in Public Madhyamic Vidhyalaya, Dharan, as per the recommendation Batch of Tuberculin used for testing (PPD RT 23 with Tween 80) procured from Bacilli Calmette Guerin (BCG)

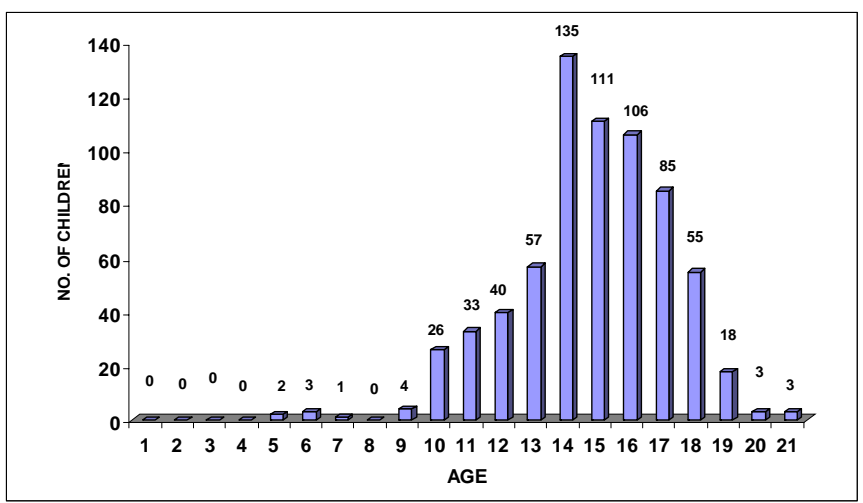

Fig. 1 : Age Distribution (in all childrens) vaccine laboratory (Madras 600 006, India). All children below 15 yrs. of age during the days of testing received (injected) 1 TU Batch of Tuberculin used for testing (PPD RT 23 with Tween 80) intradermally on flexor aspect of left forearm. The transverse diameter in mm of induration \& redness was measured after 72 - 90 hours by Tejendra Pandit, Technician and Rabina Paneru, Staff Nurse trained for the same. At the time of testing both upper arms were examined for Bacilli Calmette Guerin (BCG) scars \& transverse diameter recorded.

\section{The following data were recorded in each case:}

Injection day (1st day) - Injection date, name, age/sex , class, date of reading induration in $\mathrm{mm}$, roll no., Bacilli Calmette Guerin (BCG) scar size in mm.

Reading day (3rd or 4th day) - PPD induration in mm measured in transverse direction, reading date by trained technician supervised by senior author (N. K.).

\section{RESULT}

There were 1672 students studying in Public Madhyamic Vidyalaya, Dharan. 682 children were selected from all classes according to population proportion by simple random sampling. All 682 students received 1 TU PPD and were analyzed for tuberculin reaction.

The age distribution of 682 children ranged from 0 - 18 yrs with a mean age $14.8 \pm 2.42$ years given in figure 1 . Figure $1 \mathrm{a}$

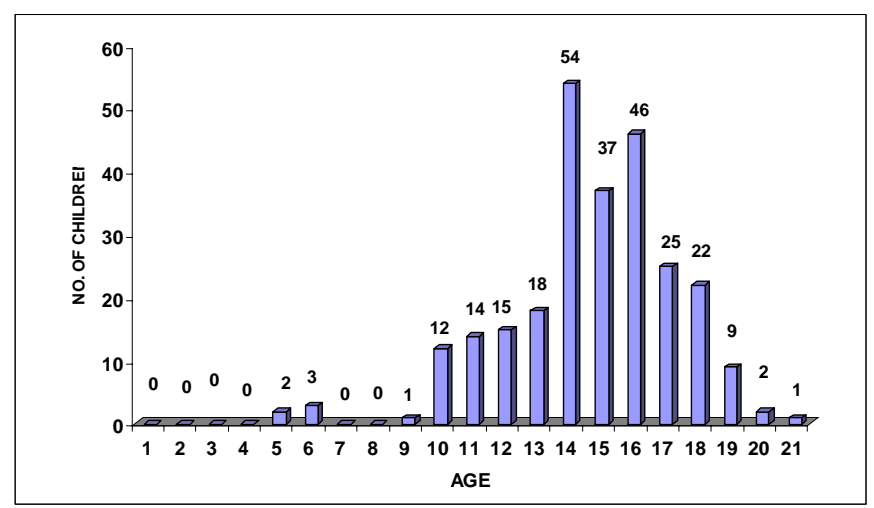

Fig. 1 (a) : Age Distribution (vacc. childrens)

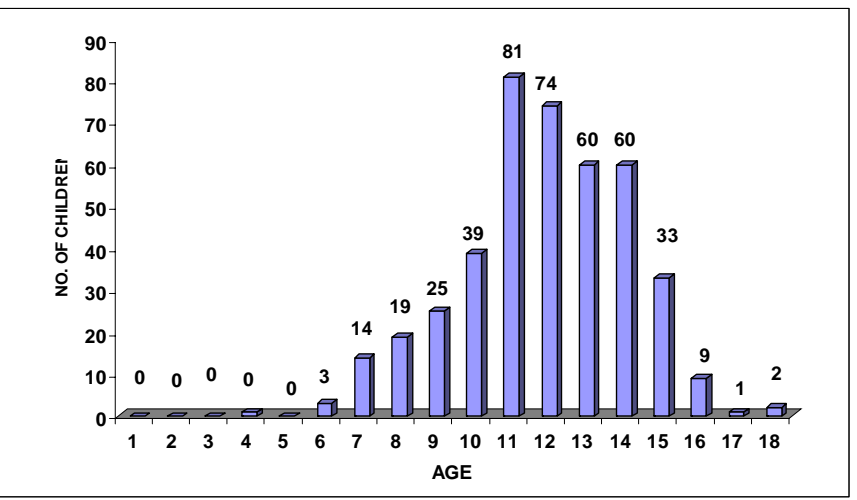

Fig. 1 (b) : Age Distribution (non vacc. childrens) 
Table I : BPKIHS, Dharan 1997, Distribution of BCG Scar by Age

\begin{tabular}{lcccc}
\hline Dharan & $4-8$ & $9-11$ & $12+$ & Total \\
Age & $\mathbf{6}$ & $\mathbf{6 3}$ & $\mathbf{6 1 3}$ & $\mathbf{6 8 2}$ \\
Total & 5 & & & \\
\hline BCG Scar & 5 & 27 & 229 & 261 \\
Positive & 1 & 36 & 382 & 421 \\
Negative & $83.3 \%$ & $42.9 \%$ & $37.5 \%$ & $38.3 \%$ \\
\% BCG & & & & \\
\hline Estimate of Prevalence and ARI & $4-8$ & $9-11$ & $12+$ & Total \\
Age & 6.1 & 10.4 & 16.5 & 14.8 \\
Mean age & 6 & 63 & 613 & 682 \\
No. Exam & 1 & 20 & 208 & 229 \\
Positive & $16.7 \%$ & $31.7 \%$ & $51.6 \%$ & $33.6 \%$ \\
Percentage & & & & \\
95\% CI & 21.2 & 38.5 & 68.1 & 40.2 \\
Upper Limit & 12.2 & 24.9 & 35.1 & 27.0 \\
Lower Limit & - & $2.7 \%$ & $1.31 \%$ & $2.44 \%$ \\
Av. ARI & - & $3.2 \%$ & $1.75 \%$ & $2.98 \%$ \\
Upper Limit & - & $2.2 \%$ & $0.87 \%$ & $1.90 \%$ \\
Lower Limit & & & & \\
\hline
\end{tabular}

Table II : JICA / NTC 1994

\begin{tabular}{|c|c|c|c|c|c|}
\hline Age & $0-5$ & $6-8$ & $9-11$ & $12+$ & Total \\
\hline \multicolumn{6}{|l|}{ Morang } \\
\hline Total & 77 & 568 & 552 & 132 & 1329 \\
\hline \multicolumn{6}{|l|}{ BCG scar } \\
\hline Positive & 39 & 270 & 213 & 39 & 561 \\
\hline Negative & 38 & 298 & 339 & 93 & 768 \\
\hline$\%$ BCG & $50.6 \%$ & $47.5 \%$ & $38.6 \%$ & $29.5 \%$ & $42.2 \%$ \\
\hline \multicolumn{6}{|l|}{ Saptari } \\
\hline Total & 239 & 924 & 1074 & 226 & 2463 \\
\hline \multicolumn{6}{|l|}{ BCG scar } \\
\hline Positive & 165 & 622 & 697 & 142 & 1626 \\
\hline Negative & 74 & 302 & 377 & 84 & 837 \\
\hline$\%$ BCG & $69.0 \%$ & $67.3 \%$ & $64.9 \%$ & $62.8 \%$ & $66.1 \%$ \\
\hline \multicolumn{6}{|c|}{ JICA / NTC 1994} \\
\hline Age & $0-5$ & $6-8$ & $9-11$ & $12+$ & Total \\
\hline Mean age & 4.57 & 7.11 & 10.03 & 12.19 & 8.82 \\
\hline No. Exam & 97 & 536 & 665 & 155 & 1453 \\
\hline Positive & 19 & 94 & 142 & 40 & 285 \\
\hline Percentage & 19.6 & 17.5 & 21.3 & 25.8 & 19.6 \\
\hline
\end{tabular}

95\% CI

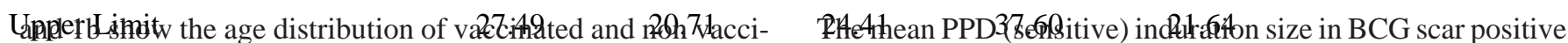

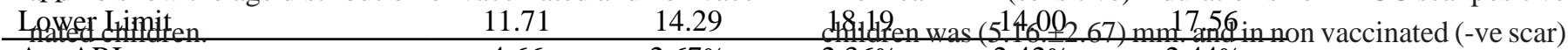

Av ARI

$4.66 \quad 2.67 \%$

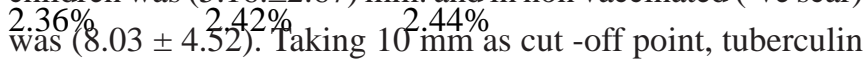
95\% CI

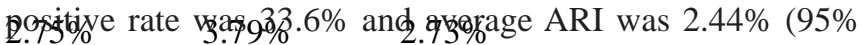
Upheperfintage of BCG coverage (B6.69\%ar rate) was $13 \%$.3\% Liow

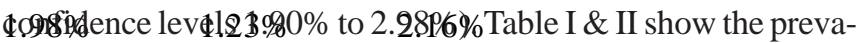
in age group of $4-8$ yrs. and 37.5\% in children above 12 lence rate and average ARI in each age group of this study and yrs. $(\mathrm{P}=0.00157)$, which was highly significant (Table I). average Annual Risk of Infection (ARI) of schools in Saptari (2.49\%) and Morang (2.38\%) compared with earlier report.

The PPD induration size is shown in Figure 2 for all children. 
Table III : Nepali Studies Deriving an Estimation of ARI ${ }^{\text {5-10 }}$

* Different estimates of ARI depending on differing definition of infected.

Fig. 2 : PPD in Duration Size in MM (for all children)

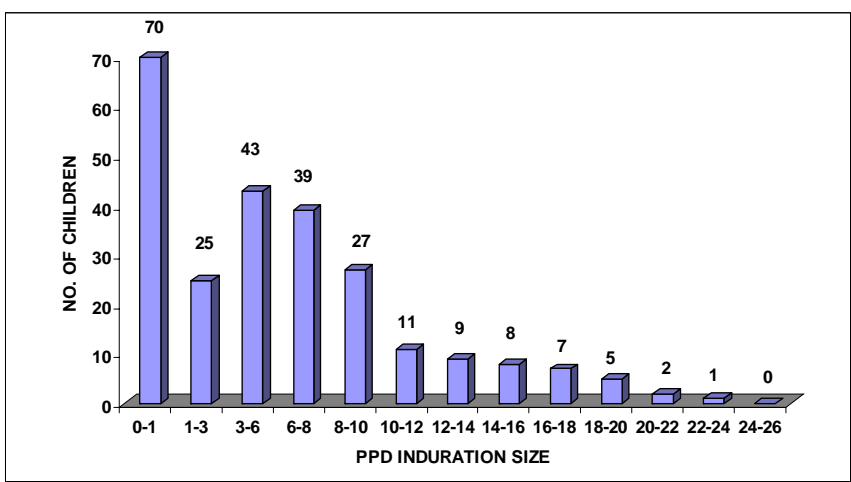

Fig. 2(a) : PPD in Duration Size in mm (for BCG Scar +ve children)

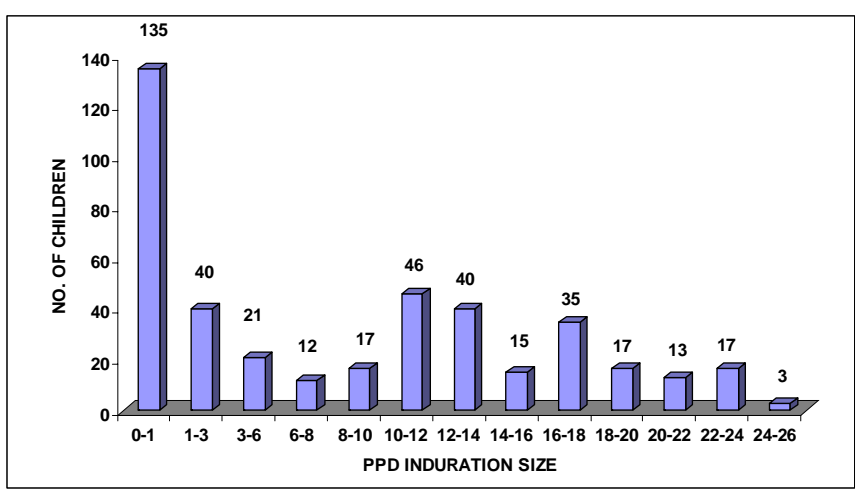

Fig. 2(b) : PPD in Duration Size in mm (for BCG Scar -ve children)

\section{DISCUSSION}

Different districts of Eastern Development Region (EDR) show different Bacilli Calmette Guerin (BCG) coverage. Dharan is having 83.3\% coverage among 4-8 age group which is decreasing gradually. BCG programme is better in Dharan as compared to Morang (48\%) and Saprari (68\%), though EPI started BCG coverage since 1977. May be the coverage was poor during 80's - 90's. BCG coverage by EPI has increased yearly. This could be the reason of scar -ve in older children in Dharan as elsewhere. Further extensive study is required to know the exact situation in this area and an awareness program regarding $\mathrm{BCG}$ is required.

\section{Average ARI}

The average ARI is $2.44 \%$ which suggests that tuberculosis is highly epidemic in this area. Table III shows ARI data of other districts. Although Dharan is having migratory population, poor hygienic condition and over-crowding exists in households.

Population density may be one factor which influences tuberculosis in this area.

\section{Recommendation}

Tuberculin survey is required in Sunsari district area. Follow up survey is also suggested in Dharan as this survey was limited to only one school due to various reasons. Intensive tuberculosis programme is necessary to give impact to tuberculosis control as this city may be a focal point of transmission to tuberculosis infection due to high migratory population. 
Short course chemotherapy is being given to all sputum +ve cases in Dharan under close supervision, so the survey should be repeated to see the impact of program in coming years.

Nation Tuberculosis Centre (NTC) should co-operate with B.P. Koirala Institute of Health Sciences, Dharan for further research.

\section{REFERENCES}

1. The WHO Tuberculin test. committee on epidemiology and stastistic (F. Deck \& J. Guld) published in bulletin. int. un. ag. Tuberc. 1962, 32 (No. 1) 88 .

2. Tuberculin survey's in Nepal. Dr. T. M. Shakya, NTC. Published in proceedings of National Seminar / Workshop Nov. 1992. HMGN, JICA, NTC.

3. Certain characteristics of BCG. Induced tuberculin sensitivity. Bulletin. WHO 1955, 12, 123 - 141.

4. The tuberculin skin test. American thoracic society, Medical section of the American Lung Association. March - 1981.
5. Tuberculosis in Gorkha district Nepal (part 3 Tuberculin sensitivity), TCSP (Gorkha project), UMN

6. INF Tuberculin survey in Banke district, Nepal 1993.

7. INF Tuberculin survey in Dang district, Nepal 1990 / 92

8. Tuberculin sample surveys in four districts of central development region of Nepal, NTC, Dr. Thir Man Shakya.

9. PPD RT 23 tuberculin survey Surkhet district Nepal 1988 / 1989 INF

10. A comprehensive report on the Nepal - Japan technical cooperation project for NTP (August 1987 - April 1993), HMG of Nepal, MOH, NTC, JAT for NTP

11. Statistical year book of Nepal 1991 and 1993, Central Bureau of Statistics.

12. Tuberculosis control strategy in Nepal. M. Aoki, RITB, JATA, I. Onozaki. (JICA)

13. Nepal in Maps, educational enterprise Pvt. Ltd., S.H. Shrestha.

14. Tuberculosis control. The research institute of Tuberculosis, Japan Anti - Tuberculosis Association. 